\title{
A study to evaluate effect of different surface treatment on osteoblastic activity of zirconia implant material - An invitro study
}

\author{
Roseline Meshramkar ${ }^{1 *}$, Praveen kumar Shetty ${ }^{2}$, Gouri V Anehosur ${ }^{1}$, Aishwarya Naik ${ }^{1}$ and Lekha KP ${ }^{1}$ \\ ${ }^{1}$ Department of Prosthodontics, SDM College of dental sciences, Dharwad, India \\ ${ }^{2}$ Department of Biochemistry, SDM College of medical sciences, Dharwad, India
}

\begin{abstract}
The success of endosseous implants is directly related to the principle of osseointegration. As the surface topography of a biomaterial has a major impact on osseointegration. The aim of this study is to investigate the effect of different surface treatment on the osteoblastic activity of zirconia. A total of 60 samples of Zirconia discs was fabricated and divided into three groups. Group 1[n-20]: Zirconia without treatment; Group 2 [n-20]: Zirconia treatment with sand blasting / acid etching; Group 3 [n-20]: Zirconia treatment with UV light. After, the surface treatment all the three groups were subjected to SEM scanning electron microscope to determine the surface roughness and topography. Human osteoblastic sarcoma cells were seeded on the test material at density of $1 \mathrm{X} 104 \mathrm{cells} / \mathrm{cm}{ }^{2}$ and incubated for 48 hrs at $37+1^{0} \mathrm{c}$ under humidified atmosphere containing $5 \% \mathrm{CO}_{2}$. After 48 hours cell seeded test material and glass cover slips was fixed with $2.5 \%$ glutaraldehyde. SEM was done to evaluate adhesion of osteoblastic cells and colony formation on the zirconia discs and compared between the groups. There was marked osteoblast adhesion seen in the zirconia discs treated with UV light followed by etching and sand blasting, as compared to zirconia discs without surface treatment. The cell adhesion in Group I Samples were having less spread of Osteoblastic cells and had fewer osteoblastic cell colonies. Group II Samples were having more distinct spread of osteoblastic cells than group I. However, they had fewer osteoblastic cell colonies. The cell adhesion seen in group III (UV Photofunctionalisation) were showing more prominent osteoblast cells that was scattered throughout the Sample and showed better adhesion as compared to Group I and Group II.
\end{abstract}

\begin{abstract}
Abbreviations: SEM: Scanning electron microscopy; BIC: Bone implant contact.
\end{abstract}

\section{Introduction}

Dental implants have been accepted as a predictable and reliable treatment modality for the rehabilitation of both partially and completely edentulous patients.

Titanium so far have been the material of choice in implant dentistry [1]. However, the grey color of titanium impairs esthetic results particularly in presence of thin mucosal biotype [2]. Recently, zirconia has been widely used as dental implant substrate due to its excellent properties. Zirconia offers high flexural strength and high fracture toughness, optimal esthetics, and high biocompatibility $[3,4,5]$. The success of endosseous implants is directly related to the principle of osseointegration, a process of implant bone interaction that finally leads to bone-to-implant anchorage [6]. Osseointegration is biological fixation of implant relating to direct bone to implant contact (BIC) without an intervening connective tissue layer [7]. BIC is regarded as key indicator for successful osseointegration which governs the overall success and survival of implants [8]. Surface properties of a biomaterial play a fundamental role in osseointegration process [9]. Increased surface roughness of dental implants resulted in greater bone apposition and reduced healing time. Different approaches are being used in an effort to improve surface properties of zirconia as airborne-particle abrasion, acid etching with hydrochloric or hydrofluoric acids, plasma spraying [10-13] aggregation of bioactive materials such as hydroxyapatite [1013] and more recently, ultraviolet radiation has been used to increase the hydrophilic properties of the zirconia implants [14]. Although there has been considerable discussion of zirconia surface modification and structure, the information available about osseointegration responses and the implant-bone interaction of these implants is still far from sufficient. Thus, the optimal surface topography for a dental implant remains unclear. A research has focused on improving the surface bioactivity of zirconia-based materials in order to enhance the bone-toimplant contact as well as the speed of bone formation, to reach optimal standards.

Therefore, attempts have been made to alter the surface characteristics of zirconia. There are conflicting reports of research done, about the expected biological response of bone tissue to zirconia implants with different surface treatments. The aim of this study was to investigate the effect of different surface treatment on the osteoblastic activity of zirconia.

\section{Materials and methods}

A total of 60 samples of Zirconia discs were fabricated and divided into 3 groups.

${ }^{\star}$ Correspondence to: Roseline D Meshramkar, Professor and HOD, Department of prosthodontics, SDM College of dental sciences, Dharwad, Karnataka-580009, India, Tel. 9480127869, E-mail: roselinemeshramkar@yahoo.co.in

Key words: zirconia implant, surface treatment, osteoblastic activity, acid etching, sandblasting, UV functionalization

Received: January 02, 2019; Accepted: January 15, 2019; Published: January 17, 2019 
Group1(n-20)

Group $2(\mathrm{n}-20)$

Group 3 (n-20)

In this study two surface treatment was done and Surface roughness and topography of zirconia was determined for cell adhesion and colony formation.

Group 1[n-25]: Zirconia without treatment

Group 2 [n-25]: Zirconia treatment with sand blasting / acid etching

Group 3 [n-25]: Zirconia treatment with UV light

After the surface treatment all the three groups were subjected to SEM scanning electron microscope to determine the surface roughness and topography. To determine osteoblastic activity, osteoblast was procured and the cells were grown in cell culture lab and cell adhesion tests were performed on zirconia discs for all the groups. Human osteoblastic sarcoma cells were seeded on the test material at density of $1 \mathrm{X} 104$ cells $/ \mathrm{cm}^{2}$ and incubated for 48 hrs at $37+1^{0} \mathrm{c}$ under humidified atmosphere containing $5 \% \mathrm{CO}_{2}$ (Figures 1, 2 and 3). After $48 \mathrm{hrs}$ cell seeded test material and glass cover slips were fixed with $2.5 \%$ glutaraldehyde. SEM analysis was done after the surface treatment and cell seeding on zirconia discs to evaluate adhesion of osteoblastic cells and colony formation and it was compared between the groups.

\section{Results}

After surface treatment all three groups were subjected to SEM scanning electron microscope to determine the surface roughness and topography. The following results were obtained. Group 1 (Control) showed few parallel lines, pits and cracks on the surface. Group 2(Surface treated with acid etching and Sandblasting) showed Porous surface with prominent surface Changes with elevations and depressions. Group 3(Surface treated with UV Radiation- showed lines, pits and cracks on the surface (Figures 4 and 5).

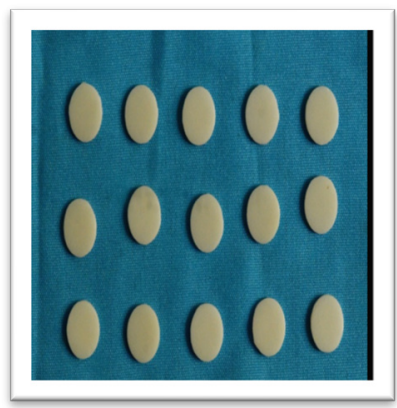

Figure 1. GROUP I (Control) - Zirconia discs without surface treatment
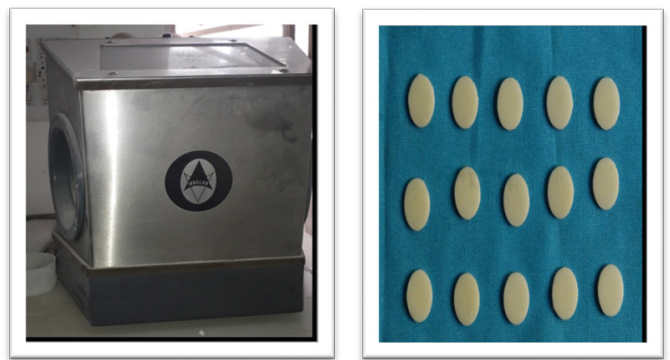

Figure 2. GROUP II - Zirconia discs surface treated by sandblasting and acid etching

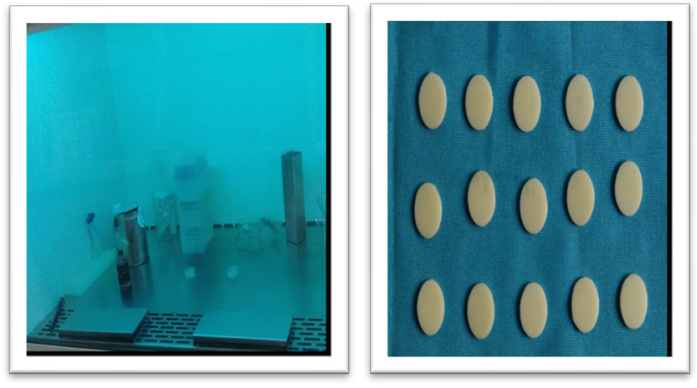

Figure 3. GROUP III - Zirconia discs surface treated by UV radiation

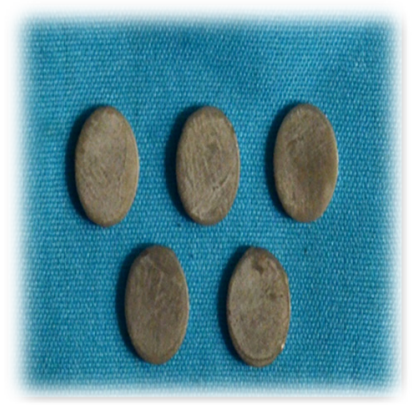

Figure 4. Dry specimen mounted on a stud using adhesive and epoxy resin, splutter coated with gold before examining it with microscope. It is done before and after cell culture. Magnification- 500 x 5000

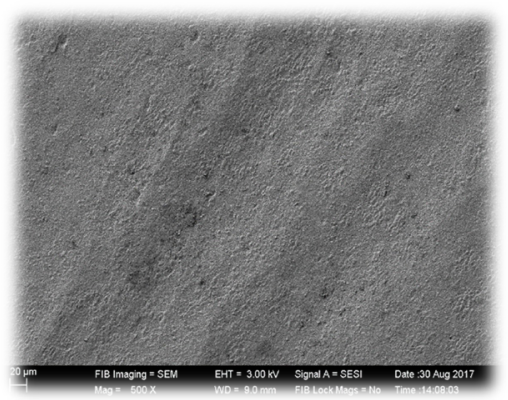

Figure 5. Group 1(Control) showing few parallel lines, pits and cracks on the surface

SEM analysis was done after the cell seeding on zirconia discs to evaluate adhesion of osteoblastic cells and colony formation and it was compared between the groups.

In group 1(control) - SEM analysis, Osteoblastic activity was seen with very Few colonies. In group 2(Surface treated with acid etching and Sandblasting)-SEM analysis showed Osteoblastic activity with More colonies. In group 3 SEM analysis showed maximum number of colonies will characteristic cell morphology (Figures 6). Osteoblastic cell was very prominent and scattered throughout the sample and showed better adherence as compared to group 1(control) and group 2 (surface treated with acid etching and sandblasting). Osteoblastic cells had attached well throughout the surface. The SEM analysis demonstrated polygonal osteoblastic cells, filopodial attachment and growth on group 3 (Zirconia treated with UV radiation photofunction).

\section{Discussion}

Zirconia ceramic is currently considered an attractive and advantageous endoosseous dental implant material. There has been much focus on improving the surface bio activity of zirconia-based 


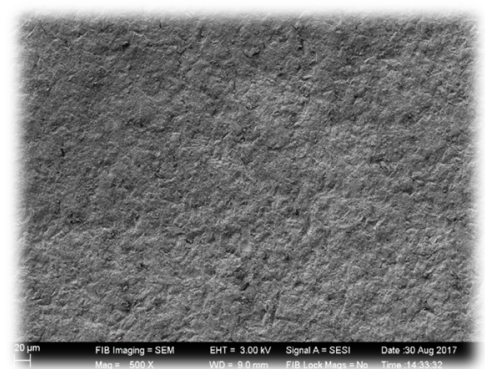

Figure 6. Group 2 (Surface treated with acid etching and Sandblasting) showed porous surface with prominent surface changes with elevations and depressions

materials in order to enhance the bone to implant contact as well as the speed of bone formation to reach optimal standard roughened implant surface. Different surface roughening procedures were studied in order to enhance surface characteristics of zirconia implants, thus improving osseointegration. Implant material composition and surface topography influence the wound healing processes following the implantation and subsequently affect osseointegration [8]. A moderately rough surface topography is known to positively affect the interfacial tissue reaction $\mathrm{A}$ research has focused on improving the surface bioactivity of zirconia-based materials in order to enhance the bone-to-implant contact as well as the speed of bone formation, to reach optimal standards. Different surface roughing procedures were studied in order to enhance surface characteristics of zirconia implants, thus improving osseointegration [10,18,32]. In 2003 Scarano, et al. [17] examined the bone-implant interface of machined zirconia implants at 4 weeks of healing and reported BIC values of $68.4 \%$. Similarly, Akagawa, et al. [18] observed a BIC ratio of $66 \%$ to $81 \%$ for zirconia implants inserted into mandible of monkeys after 24 months of healing which was similar to that of zirconia implants at the 12-month observation.in our study zirconia samples without surface treatment had osteoblastic cell adherence, Gahlert, et al. [15 ] confirmed that the increased surface roughness of sandblasted and acid etched zirconia implants (Figures 7 , $8,9$ and 10$)$.

The osseointegration capacity of machined zirconia surface is substantially increased after modification by sandblasting [19]. However, Gahlert, et al. [15] specified that further improvements in the surface roughness of zirconia implants are needed. As the review only included animal studies, the analysis of each surface modification was hindered by the limited number of studies, and only the two surface modifications (acid etching or blasting) were compared with titanium implants. and surface grinding resulted in structural damage, material loss, grain pullout, and induction of micro cracks, causing zirconia to crack under functional loading [20,21,22]. Many studies Gahlert, Deprich demonstrated increased osseointegration with acid etched zirconia which is similar to our findings where we observed increased oseoblastic activity with surface treated with both sand blasting and etching were shown. Kohal, et al. assessed the hard and soft tissue conditions of sand blasted zirconia implants, comparing them with acid-etched and sand blasted titanium implants. The value of mean mineralized BIC obtained after five months of loading and nine months of healing were $72.9 \%$ and $67.4 \%$ for titanium and zirconia implants respectively [23]. BIC of chemically altered titanium implants and SLA zirconia implants. A surface that is termed rough in one study may be termed smooth in another. In addition, tissue response to altered surface topography need not necessarily reflect the performed change of the surface alone. When the surface topography is changed, the surface chemistry or physics may change simultaneously [24]. Recently, ultraviolet (UV)-mediated photo functionalization of titanium implants has been proposed to enhance the adhesive property of titanium to the bone. Photofunctionalized implants showed a near 100\% BIC and three

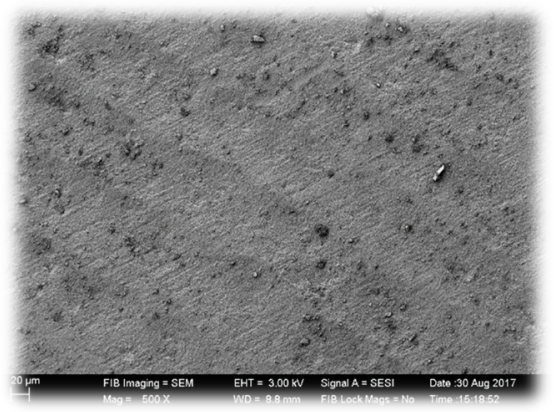

Figure 7. Group 3 Surface treated with UV Radiation- showed lines, pits and cracks on the surface

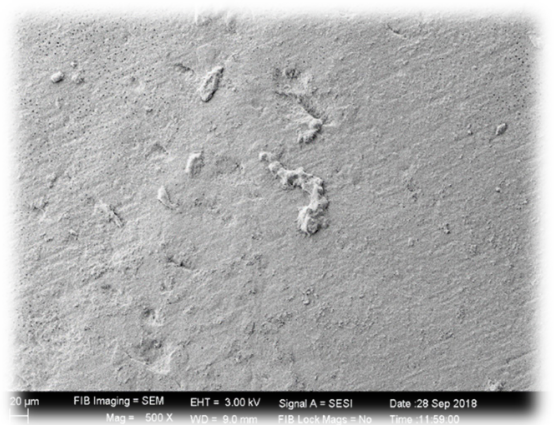

Figure 8. In group 1(control) - SEM analysis, osteoblastic activity was seen with very few colonies

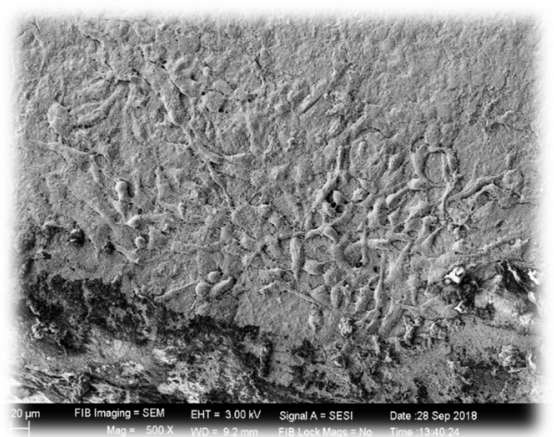

Figure 9. In group 2 (Surface treated with acid etching and Sandblasting)-SEM analysis showed osteoblastic activity with more colonies

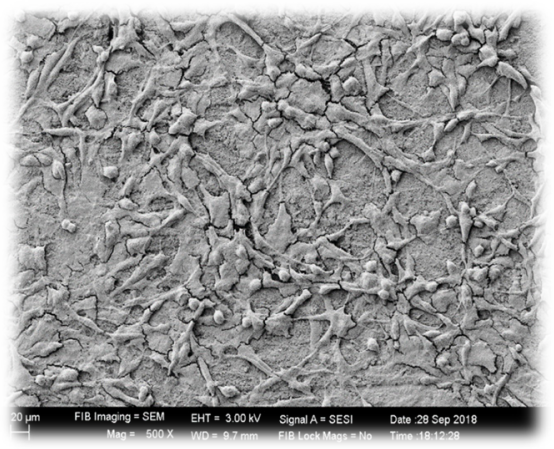

Figure 10. In group $3 \mathrm{SEM}$ analysis showed maximum number of colonies will characteristic cell morphology 
times the strength of osseointegration in animal models [11,12]. Liu, et al. [21] in 2005 demonstrated that zirconia posess photo catalytic activity when exposed to UV light by removal of hydrophobic layer of hydrocarbons from the surface of the material. In our study we found that there was increased osteoblastic activity after UV Radiation which is in accordance with study conducted by Att, et al. [25] in 2009, UV light treatment transformed the zirconia surface from hydrophobic to hydrophilic status. It has been particularly challenging to enhance the osteoconductive capacity of zirconia by its surface topographical modification. Further research to be done to focus on Material changes after surface treatment. Effect of UV light on in vivo on osteoconductive potential of zirconia should be the target of exploration [26]. Further animal studies should be carried out. This being an invitro study cannot fully translate into in vivo conditions. In vivo conditions tissue response has to be evaluated.

\section{Conclusion}

Within the limitations of the study, the following conclusion was withdrawn

1. The cell adhesion in Group I Samples were having less spread of osteoblastic cells and had fewer osteoblastic cell colonies.

2. Group II Samples were having more distinct spread of osteoblastic cells than group I. However they had fewer osteoblastic cell colonies.

3. The cell adhesion seen in group III (UV Photofunctionalisation) were showing more prominent osteoblast cells that was scattered throughout the sample and showed better adhesion as compared to Group I and Group II.

\section{Acknowledgement}

We would like to acknowledge Rajiv Gandhi University of Health Sciences Bangalore for their grant for the research. RGU/ADV.RES/ GRANTS/059/2016-17.

\section{References}

1. Hisbergues M, Vendeville S, Vendeville P (2009) Zirconia: Established facts and perspectives for a biomaterial in dental implantology. $J$ Biomed Mater Res B Appl Biomater 88: 519-529. [Crossref]

2. Özkurt Z, Kazazoglu E (2011) Zirconia dental implants: a literature review. J Oral Implantology 37: 367-376.

3. Kelly JR, Denry I (2008) Stabilized zirconia as a structural ceramic: an overview. Dent Mater 24: 289-298. [Crossref]

4. Zarone F, Russo S, Sorrentino R (2011) From porcelain-fused-to metal to zirconia: clinical and experimental considerations. Dent Mater 27: 83-96.

5. Uo M, Sjögren G, Sundh A, Watari F, Bergman M, et al. (2003) Cytotoxicity and bonding property of dental ceramics. Dent Mater 19: 487-492. [Crossref]

6. Ewais $\mathrm{OH}, \mathrm{Al} \mathrm{AF}$, Ghoneim MM, Aboushelib MN (2017) Novel zirconia surface treatments for enhanced osseointegration. J Adv Prosthodont 9: 104-109.

7. Parithimarkalaignan S, Padmanabhan TV (2013) Osseointegration: An update. J Indian Prosthodontist Society 13: 2-6.
8. Gahlert M, Roehling S, Sprecher CM, Kniha H, Milz S, et al. (2012) In vivo performance of zirconia and titanium implants: a histomorphometric study in mini pig maxillae. Clin Oral Implants Res 23: 281-286. [Crossref]

9. Requirements for ensuring a long-lasting, direct bone-to-implant anchorage in man Acta Orthop Scand 52: 155-170. [Crossref]

10. Bauer S, Schmuki P, von der Mark K, Park J (2013) Engineering biocompatible implant surfaces. Part I: materials and surfaces. Progress in Materials Science 58: 261-326.

11. Buser D, Broggini N, Wieland M, Schenk RK, Denzer AJ, et al. (2004) Enhanced bone apposition to a chemically modified SLA titanium surface. J Dent Res 83: 529-533. [Crossref]

12. Rocchietta I, Fontana F, Addis A, Schupbach P, Simion M (2009) Surface-modified zirconia implants: tissue response in rabbits. Clin Implant Dent Relat Res 20: 844-850.

13. Langhoff JD, Voelter K, Scharnweber D, et al. (2008) Comparison of chemically and pharmaceutically modified titanium and zirconia implant surfaces in dentistry: a study in sheep. Int J Oral Maxillofac Surg 37: 1125-1132.

14. Att W, Takeuchi M, Suzuki T, Kubo K, Anpo M, et al. (2009) Enhanced osteoblast function on ultraviolet light-treated zirconia. Biomaterials 30: 1273-1280.

15. Gahlert M, Gudehus T, Eichhorn S, Steinhauser E, Kniha H, Erhardt W (2007) Biomechanical and histomorphometric comparison between zirconia implants with varying surface textures and a titanium implant in the maxilla of miniature pigs. Clin Oral Implants Res 18: 662-668.

16. Depprich R, Zipprich H, Ommerborn M, Mahn E, Lammers L, et al. (2008) Osseointegration of zirconia implants: an SEM observation of the bone-implant interface. Head Face Med 4: 25. [Crossref]

17. Scarano A, Di Carlo F, Quaranta M, Piattelli A (2003) Bone response to zirconia ceramic implants: an experimental study in rabbits. J Oral Implantol 29: 8-12. [Crossref]

18. Akagawa Y, Hosokawa R, Sato Y, Kamayama K (1998) Comparison between freestanding and tooth-connected partially stabilized zirconia implants after two years' function in monkeys: a clinical and histologic study. J Prosthet Dent 80: 551-558. [Crossref]

19. Kohal RJ, Bächle M, Renz A, Butz F (2016) Evaluation of alumina toughened zirconia implants with a sintered, moderately rough surface: an experiment in the rat. Dental Materials 32: 65-72. [Crossref]

20. Aboushelib MN, Wang H (2010) Effect of surface treatment on flexural strength of zirconia bars. J Prosthet Dent 104: 98-104.

21. Liu SY, Chen IW (1991) Fatigue of yttria-stabilized zirconia: I, fatigue damage, fracture origins, and lifetime prediction. J Am Ceram Soc 74: 1197-1205.

22. Denry IL, Holloway JA (2006) Microstructural and crystallographic surface changes after grinding zirconia-based dental ceramics. J Biomed Mater Res B Appl Biomater 76: $440-448$.

23. Kohal RJ, Weng D, Bachle M, Strub JR (2004) Loaded custom-made zirconia and titanium implants show similar osseointegration: an animal experiment. J Periodontol 75: $1262-1268$.

24. Langhoff JD, Voelter K, Scharnweber D, Schnabelrauch M, Schlottig F, et al. (2008) Comparison of chemically and pharmaceutically modified titanium and zirconia implant surfaces in dentistry: a study in sheep. Int J Oral Maxillofac Surg 37: 11251132. [Crossref]

25. Aita H, Hori N, Takeuchi M, Suzuki T, Yamada M, et al. (2009) The effect of ultraviolet functionalization of titanium on integration with bone. Biomaterials 30: 1015-1025. [Crossref]

26. Ogawa T (2014) Ultraviolet photofunctionalization of titanium implants. Int J Oral Maxillofac Implants 29: e95-102. [Crossref]

Copyright: (C2019 Meshramkar RD. This is an open-access article distributed under the terms of the Creative Commons Attribution License, which permits unrestricted use, distribution, and reproduction in any medium, provided the original author and source are credited. 